\title{
Transcriptome Analysis of a Ustilago maydis ust1 Deletion Mutant Uncovers Involvement of Laccase and Polyketide Synthase Genes in Spore Development
}

\author{
Emir Islamovic, ${ }^{1}$ María D. García-Pedrajas, ${ }^{2}$ Nadia Chacko,,${ }^{1}$ David L. Andrews, ${ }^{1}$ Sarah F. Covert, ${ }^{3}$ and \\ Scott E. Gold' \\ ${ }^{1}$ Department of Plant Pathology, University of Georgia, Athens, 30602, U.S.A.; ${ }^{2}$ Instituto de Hortofruticultura Subtropical y \\ Mediterránea "La Mayora", Universidad de Málaga-Consejo Superior de Investigaciones Científicas (IHSM-UMA-CSIC), \\ Estación Experimental “La Mayora”, 29750 Algarrobo-Costa, Málaga, Spain; ${ }^{3}$ Warnell School of Forestry and Natural \\ Resources, University of Georgia, Athens, GA, 30602, U.S.A.
}

Submitted 14 May 2014. Accepted 1 September 2014.

Ustilago maydis, causal agent of corn smut disease, is a dimorphic fungus alternating between a saprobic budding haploid and an obligate pathogenic filamentous dikaryon. Maize responds to $U$. maydis colonization by producing tumorous structures, and only within these does the fungus sporulate, producing melanized sexual teliospores. Previously we identified Ust1, an APSES (Asm1p, Phd1p, Sok2p, Efg1p, and StuAp) transcription factor, whose deletion led to filamentous haploid growth and the production of highly pigmented teliospore-like structures in culture. In this study, we analyzed the transcriptome of a ust 1 deletion mutant and functionally characterized two highly upregulated genes with potential roles in melanin biosynthesis: um05361, encoding a putative laccase (lac1), and um06414, encoding a polyketide synthase (pks1). The $\Delta l a c 1$ mutant strains showed dramatically reduced virulence on maize seedlings and fewer, less-pigmented teliospores in adult plants. The $\Delta p k s 1$ mutant was unaffected in seedling virulence but adult plant tumors generated hyaline, nonmelanized teliospores. Thus, whereas pks1 appeared to be restricted to the synthesis of melanin, lac1 showed a broader role in virulence. In conclusion, the ust1 deletion mutant provided an in vitro model for sporulation in $U$. maydis, and functional analysis supports the efficacy of this in vitro mutant analysis for identification of genes involved in in planta teliosporogenesis.

Ustilago maydis, the causal agent of corn smut disease, is a heterothallic member of the phylum Basidiomycota with a dimorphic life cycle consisting of a saprobic budding asexual

Current address for E. Islamovic: BASF, 26 Davis Dr., Research Triangle Park, NC 27709, U.S.A.

Current address for N. Chacko: Department of Biology, Texas A\&M University, College Station, TX 77843, U.S.A.

Current address for S. E. Gold: United States Department of AgricultureAgricultural Research Service, Russell Research Center, Toxicology \& Mycotoxin Research Unit, Athens, GA, 30605, U.S.A.

Corresponding author: S. Gold; E-mail: Scott.Gold@ars.usda.gov

This article is in the public domain and not copyrightable. It may be freely reprinted with customary crediting of the source. The American Phytopathological Society, 2015. phase and a filamentous parasitic phase (Christensen 1963; Holliday 1974). In the parasitic phase, filamentous fungal cells penetrate maize tissue, primarily the silks (stigmas), and enter developing ovaries. During infection, hyphae proliferate, inducing plant cell division and expansion, eventually forming massive smut galls. Inside the galls, darkly pigmented teliospores form, which give the maize ear a burnt, sooty appearance, hence, the disease name "smut." Galls rupture and the spores are spread by wind and rain. In the spring, spores germinate and yield saprobic budding cells. Compatible budding cells are then able to mate and produce infectious filamentous cells, completing the life cycle (Christensen 1963; Holliday 1974).

The U. maydis dikaryon is an obligate biotroph; teliospore production occurs exclusively in in planta tumors. Efforts have been made to elucidate the distinctive fungal development program leading to the formation of mature diploid teliospores. The morphological events during this process have been analyzed in detail, especially in galls formed in leaves and stems (Banuett and Herskowitz 1996). Fungal proliferation within plant tumors is associated with an increase in branching. Increasingly shorter branches formed especially at the hyphal tip appear to signal the switch from vegetative to sporogenous hyphae (Banuett and Herskowitz 1996). At this late stage of tumor development, the fungus is mostly found in aggregates embedded in a mucilaginous matrix (Banuett and Herskowitz 1996; Christensen 1963), which accumulates in enlarged apoplastic regions (Doehlemann et al. 2009). The tips of the hyphae become lobed, followed by hyphal fragmentation that produces segments of one to several cells. At this stage, karyogamy has taken place and 4',6-diamidino-2-phenylindole staining shows a single nucleus per cell (Banuett and Herskowitz 1996; Snetselaar and Mims 1994). Following fragmentation, cells undergo a process of rounding and deposition of the secondary cell walls. Cell walls are hyaline at first, becoming yellowbrown and finally dark brown, and exhibit a characteristic echinulation in mature teliospores. As the number of mature teliospores increases, tumors darken.

Although a number of genes and pathways that influence teliospore development in planta have been identified, a general understanding of the molecular mechanisms and cellular activities involved in teliosporogenesis, as well as the signals that induce the process and what makes it strictly dependent on the host plant, is lacking. Because sporogenesis takes place only in planta, experimental problems are encountered in the analysis of the process. Teliosporogenesis is not well synchro- 
nized in different tumors and, even in different parts of the same tumor, teliospores at different stages of development are encountered (Banuett and Herskowitz 1996).

In a previous study, we identified Ust1 as the closest $U$. maydis ortholog of the Aspergillus nidulans regulatory protein StuA, a member of the fungal-specific APSES (Asm1p, Phd1p, Sok2p, Efg1p, and StuAp) family of transcription factors. We showed that deletion of ustl in budding strains resulted in constitutive filamentous growth. What is more, $\Delta$ ust 1 strains produced large numbers of teliospore-like structures in culture over time (García-Pedrajas et al. 2010). Therefore, we postulated that this previously generated $\Delta u s t 1$ mutant could provide a synchronous, host-free genetic system to begin to decipher some aspects of the sporulation-associated transcriptome. We hypothesized that differential gene expression analysis in the $\Delta u s t 1$ mutant in culture would reveal genes playing roles in in planta teliospore development.

A critical step of teliospore development is pigmentation. Two main pathways of melanin synthesis are found in fungi. A few fungi synthesize melanin via L-3-4-dihydroxyphenylalanine (L-DOPA), in a pathway similar to that of mammalian melanin biosynthesis. L-DOPA molecules are oxidized by laccase and polymerized into melanin (Eisenman et al. 2007). Analysis of fungal wall pigmentation in the basidiomycete Cryptococcus neoformans (Eisenman et al. 2009) suggests a model of vesicle-associated melanization of the cell wall. In this model, small vesicles containing L-DOPA are released in the cell wall, oxidized by laccase, and polymerized into melanin. Laccase mutants were unable to produce darkly pigmented cell walls. Many other fungi produce melanin via the DHN pathway. In this pathway, the precursor is acetyl coA or malonyl coA and the first step is catalyzed by a polyketide synthase (PKS). PKS genes involved in DHN melanin biosynthesis have been characterized in a number of Ascomycota phytopathogenic fungi such as Bipolaris oryzae (Moriwaki et al. 2004) and Magnaporthe oryzae (Oh et al. 2008). Deletion of the PKS gene in $B$. oryzae produced fully virulent but melanin-deficient mutants while deletion in $M$. oryzae generated nonmelanized appressoria incapable of penetrating rice leaves.

The identification of genes encoding proteins homologous to laccase and PKS as highly induced in cultures of the ust 1 mutant by microarray analysis confirmed the utility of this strain as a tool to investigate aspects of sporulation. In this work, we focused on the functional characterization of two of those genes: a laccase-encoding gene (um05361; here named lac1) and a PKS-encoding gene (um06414; here named pks1). In mutants deleted for lacl, pigmentation was reduced but not fully abolished. Gene lacl also played a broader role in virulence because mutant strains induced reduced disease severity in seedlings. Deletion mutant analysis showed that the role of $p k s 1$, on the other hand, was restricted to dramatic effects on pigmentation both in culture and in teliospores produced in the host.

\section{RESULTS}

Transcriptome analysis of the ust 1 deletion mutant shows widespread effects on gene expression.

To identify genes potentially involved in the sporulation program, we carried out microarray analysis comparing a $U$. maydis haploid deleted for ustl (strain 14/25) with the wildtype (WT) progenitor (strain 1/2) (Table 1). Previously, we had shown that deletion of ust 1 led to filamentous growth in potato dextrose broth (PDB) cultures and, over time, to production of numerous rounded, highly melanized cells (García-Pedrajas et al. 2010). Similarly, in array medium (Scherer et al. 2006), we found that, at $24 \mathrm{~h}$, ust 1 mutant cells grew filamentously while, at $48 \mathrm{~h}$, rounded cells developed with highly pigmented, thick cell walls (Fig. 1). Total RNA was extracted from strains 14/25 and $1 / 2$ grown in array medium (Scherer et al. 2006) for 24 and $48 \mathrm{~h}$. RNA was then reverse transcribed to cDNA, labeled with $\mathrm{Cy} 3$, and hybridized onto custom one color NimbleGen arrays covering all of the then-predicted 6,869 $U$. maydis genes. Consistent with its role as a major developmental transcription factor, 808 genes were found to be differentially expressed by at least twofold when comparing the $\Delta u s t l$ strain with the WT at $48 \mathrm{~h}$. Of these genes, 184 showed greater than eightfold change, 105 of which were functionally classified and 79 unclassified via the Munich Information Center for Protein Sequences (MIPS) Functional Catalogue Database (FunCat) (Kamper et al. 2006; Ruepp et al. 2004) for various biological functions (Fig. 2). FunCat currently contains 27 main functional categories covering general cellular processes such as cellular transport, communication, and so on. Our results show that $42 \%$ of the genes induced more than eightfold were involved in metabolism. Interestingly, genes involved in protein synthesis were upregulated whereas genes involved in transcription were downregulated, perhaps suggesting elevated production of a limited set of spore-specific proteins.

Of the identified 184 greater than eightfold differentially expressed genes, 111 and 73 genes were up- and downregulated, respectively. As noted previously in Northern blots (GarcíaPedrajas et al. 2010), spore-specific protein 1 (sspl) (um12271), a gene identified as highly expressed in teliospores (Huber et al. 2002), was found on the arrays to be highly induced during production of the teliospore-like structures by the $\Delta u s t 1 \mathrm{mu}-$ tant at $48 \mathrm{~h}$. The most differential 10 upregulated and 10 downregulated genes during formation of teliospore-like structures in vitro are listed in Table 2.

Several genes upregulated in $\Delta u s t 1$ versus the WT exhibited homology to genes in other fungal species involved in spore development or pigmentation, such as um05361, similar to laccase genes; um06414 and the nearby um06418, similar to PKS genes involved in melanin synthesis (Table 2); um02035 (34fold), related to the yellowish-green 1 (aygl) gene in A. fumigatus involved in conidial pigmentation (Tsai et al. 2001); and um03522 (18-fold), related to UGA4, GABA permease, in-

Table 1. Strains of Ustilago maydis used in this study

\begin{tabular}{|c|c|c|}
\hline Strain & Genotype & Reference \\
\hline $1 / 2$ & alb1 (521) & Gold et al. 1997 \\
\hline $14 / 25$ & $a 1 b 1, \Delta u s t 1:: c b x$ & Garcia-Pedrajas et al. 2010 \\
\hline SG200 & mfal pra1 mfa2 $b W 2 b E 1$ & Bölker et al. 1995 \\
\hline SG200-1 $\Delta l a c 1$ & SG200 background, $\Delta l a c 1:: c b x$ & This study \\
\hline SG200-2 $\Delta$ lac1 & SG200 background, $\Delta l a c 1:: c b x$ & This study \\
\hline SG200-3 Dlac1 & SG200 background, $\Delta l a c 1:: c b x$ & This study \\
\hline SG200-1 $\Delta p k s 1$ & SG200 background, $\Delta p k s 1:: c b x$ & This study \\
\hline SG200-2 $\Delta p k s 1$ & SG200 background, $\Delta p k s 1:: c b x$ & This study \\
\hline SG200-3 $\Delta p k s 1$ & SG200 background, $\Delta p k s 1:: c b x$ & This study \\
\hline SG200-1 $\Delta l a c 1+l a c 1$ & SG200 background, Dlac1::cbx hygCosmid-lac1 & This study \\
\hline SG200-1 $\Delta p k s 1+p k s 1$ & SG200 background, $\Delta p k s 1:: c b x$ hygCosmid-pks1 & This study \\
\hline
\end{tabular}


volved in nitrogen storage during conidiation (Kumar and Punekar 1997). This result indicated that genuine teliospores and the spore-like structures produced by the $\Delta u s t 1$ mutant in culture share developmental features.

The 10 most dramatically downregulated genes (Table 2) were mostly noncharacterized proteins; however, Hmp1, a cruciform DNA recognition protein (Dutta et al. 1997) encoded by $u m 00496$, was downregulated 378-fold in $\Delta u s t 1$ compared with the WT. The function of this protein in U. maydis has not been determined by deletion mutant analysis but, in a proteomic approach, it was recently also found to be downregulated 5.4-fold in filamentous versus budding $U$. maydis cells (Martínez-Salgado et al. 2013). Additionally, consistent with the observed severe mating defect shown by the $\Delta u s t 1$ mutant (García-Pedrajas et al. 2010), the al mating factor, mfal (um02382) (Bölker et al. 1995), is downregulated 94-fold in the $\Delta u s t 1$ mutant at $48 \mathrm{~h}$. Finally, um00371 encodes an opsin-1 related protein. In Neurospora crassa, the nop-1 gene, the likely ortholog to um00371, is a late conidiation gene and appears to function as a repressor of some sporulation genes. Although it can bind retinal, becoming a light-absorbing pigment, its repression of con-13 was demonstrated to be in a light-independent manner (Bieszke et al. 2007).

To confirm that the $\Delta u s t l$ mutant could be used to identify genes involved in in planta spore development, in this work, we focused on the functional analysis of two genes, um05361 and um06414, upregulated 119- and 140-fold in $\Delta u s t 1$ versus the WT, respectively (Fig. 3A). BLAST searches with um05361 showed that it is highly similar to fungal laccase genes; for example, it is $54 \%$ similar to the cell-wall-associated laccase 1 (CNLAC1) from $C$. neoformans, which is a virulence factor and affects melanization of spores (Zhu and Williamson 2004). Therefore, we named um05361 lacl. A schematic comparison of functional domains of CNLAC1 and U. maydis Lac1 is shown in
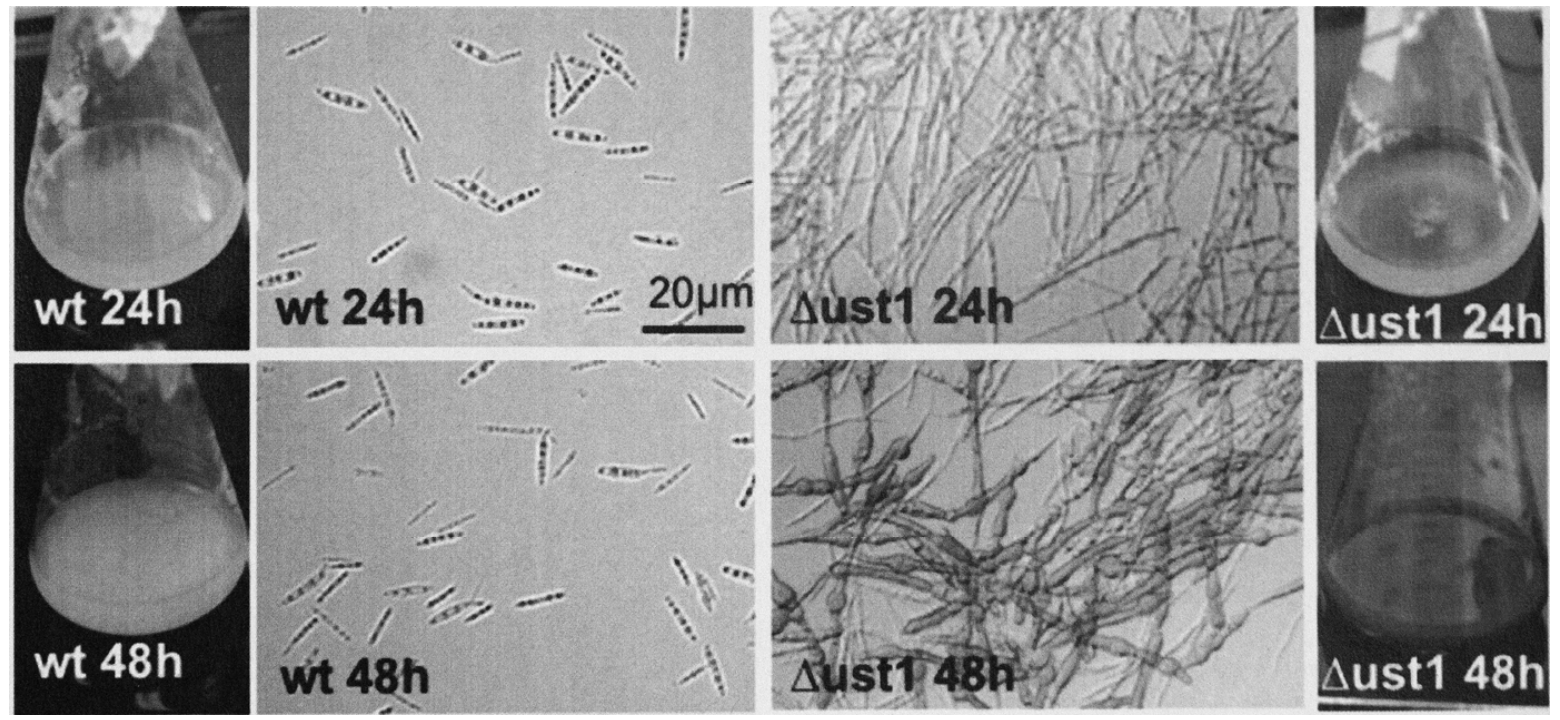

Fig. 1. Comparison of cell morphology of Ustilago maydis ust 1 deletion mutant and wild-type (WT) strains. Cultures of WT strain $1 / 2$ and ust 1 deletion mutant strain 14/25 were examined microscopically after 24 and $48 \mathrm{~h}$ of growth in array medium. SG200 grew as budding cells while the $\Delta u s t 1$ strain is constitutively filamentous, generating rounded, melanized teliospore-like structures in large numbers after $48 \mathrm{~h}$.

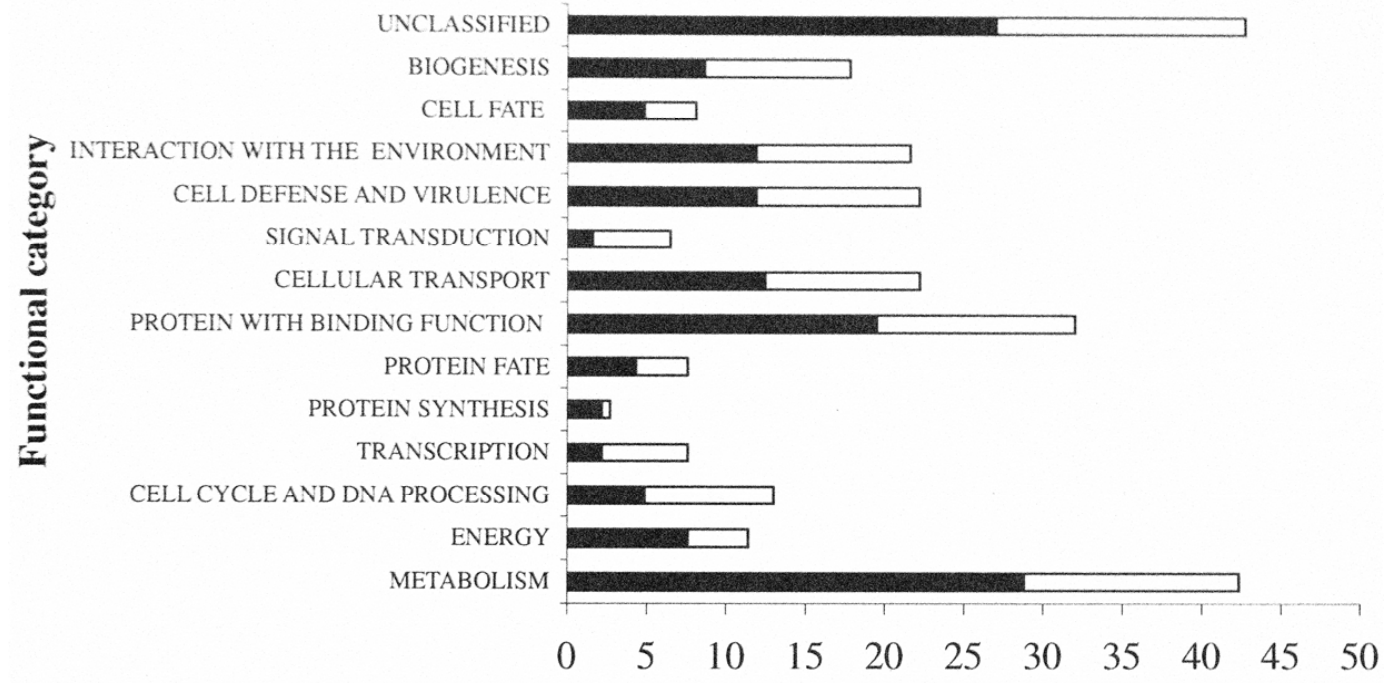

\section{Proportion of differentially regulated genes (\%)}

Fig. 2. Functional classification of genes highly differentially expressed (more than eightfold) during teliospore-like structure formation in the Ustilago maydis ustl deletion mutant. Differentially regulated genes were classified into functional groups using the MIPS FunCat database. Many genes were assigned to multiple functional categories. Solid bars represent genes that were upregulated while open bars represent those downregulated. 
Figure 3B. According to the FunCat analysis, predicted functions of laccase are extracellular lignin degradation $(P$ value $=$ 8.76e-04), metabolism of melanin $(P$ value $=4.09 \mathrm{e}-03)$, and biogenesis of cellular components (cell wall) $(P$ value $=6.84 \mathrm{e}-02)$. Secretion of laccases has been observed in other fungi (Eisenman et al. 2007; Litvintseva and Henson 2002) and the $U$. maydis Lac1 protein contains a 23-amino-acid signal peptide typical of extracellular enzymes, as predicted by the Neilsen et al. algorithm $(P=0.985)$ on the SignalP 3.0 server and Secretome 2.0 server. Using INTERPRO, laccase domains are located in $U$. maydis um05361 similar to those of CNLAC1 from $C$. neoformans (Fig. 3B). BLAST searches with um06414 indicated strong similarity with PKS genes involved in the biosynthesis of DHN melanin and, therefore, we named this gene $p k s$ l. INTERPRO identified two PKS domains in the predicted protein encoded by the $U$. maydis um06414 gene. A comparison of the predicted domain structure of Pks1 with PKS proteins from two other plant pathogens, Colletotrichum heterostrophus and Botrytis oryzae, is shown in Figure 3B. Gene um06414 (pksl) is one of only three genes found in the $U$. maydis genome that encode proteins containing the minimal PKS domains ketoacyl CoA synthase (KS) and thioesterase (TE). Gene pksl also possesses two putative acyl carrier domains. Genes involved in the synthesis and modification of these secondary metabolites are often clustered together and are co-expressed (Khaldi et al. 2008). Consistently, pks 1 appears to be part of a secondary metabolism gene cluster which contains a second highly upregulated PKS gene, um06418 (Table 2), which, in addition to the KS and TE domains, contains an acyl transferase (AT) domain but lacks the critical phosphopantetheine binding domains. It was previously speculated that, because neither um06414 nor um06418 individually possess all the critical domains but, in combination, they do, they likely act together (Bölker et al. 2008).

Quantitative real-time polymerase chain reaction (qPCR) was used to confirm and quantify differential expression of lacl, pks1, and the previously reported spore-specific protein gene sspl (um12271) (Huber et al. 2002), earlier shown to be induced in the ust1 mutant by Northern blot analysis (GarcíaPedrajas et al. 2010) and found to be upregulated 68-fold in the microarray data reported here. Expression was quantified after 24 and $48 \mathrm{~h}$ of growth in PDB (Fig. 3C) and normalized to the frequently used constitutive reference gene um03726, encoding a probable CPR1 cyclophilin, generally referred to as peptidylprolyl isomerase (ppi) (Scherer et al. 2006). All three genes were highly induced in the ustl mutant as compared with their expression in the WT $1 / 2$ strain. Interestingly, although formation of melanized teliospore-like structures in the $\Delta$ ustl strain is only prominent after $48 \mathrm{~h}$ of incubation (Fig. 1) (García-Pedrajas et al. 2010), these genes were already highly upregulated in 24-h cultures (Fig. 3C). For example, sspl was 43-fold upregulated at $24 \mathrm{~h}$ and 38-fold upregulated at $48 \mathrm{~h}$ according to the quantitative real-time PCR. The pks1 and lacl genes were upregulated 82- and 55-fold, respectively, at $24 \mathrm{~h}$, and their expression roughly doubled at $48 \mathrm{~h}$. Because of the consistency between 24- and 48-h harvest array data and the mature developmental phenotype observed at $48 \mathrm{~h}$ of growth, we focus here on the 48 -h results.

\section{Mutant analysis confirms a role for lac1 and pks1 in cell wall pigmentation.}

Using the DelsGate method (García-Pedrajas et al. 2008), the entire lacl and $p k s l$ open reading frames (ORF) were individually replaced by a plasmid containing a carboxin resistance gene (Keon et al. 1991) in the U. maydis haploid solopathogenic strain SG200 (Bölker et al. 1995). Deletion of lacl and pksl was confirmed by PCR and Southern blot analysis (Fig. 4) in three independent transformants for each gene (Table 1). All mutant strains exhibited no obvious altered phenotypes in culture; cell shape and cell growth rate in PDB medium was not notably different from the parental strain (data not shown). Solopathogenic strain SG200 is a merodiploid able to generate an active $b$ heterodimer (Table 1) and, therefore, mimics the dikaryon and grows filamentously on charcoal-amended plates. We found that this filamentation was not impaired in either $\Delta l a c 1$ or $\Delta p k s 1$ strains (data not shown).

It has been observed that, under stress conditions, including prolonged incubations, cultures of $U$. maydis become darkly pigmented (Kusch and Schauz 1989). Because we anticipated that lacl or $p k s 1$ could play a role in cell pigmentation, we investigated whether the mutations would affect this process in vitro. For that, we grew the parental and mutant strains in yeast extract-peptone-sucrose (YEPS) until mid- to late-logarithmic phase and then transferred them at several different cell concentrations to PDB and incubated them for an additional $96 \mathrm{~h}$ at $34^{\circ} \mathrm{C}$ to enhance stress (discussed below). The $\Delta l a c 1$ and $\Delta p k s 1$ strains complemented with autonomously replicating

Table 2. Top 10 most up- and downregulated genes in $\Delta u s t 1$ after $24 \mathrm{~h}$ of growth in array medium

\begin{tabular}{llc}
\hline Locus & \multicolumn{1}{c}{ Ustilago maydis annotation } & Fold change $^{\mathbf{z}}$ \\
\hline Upregulated genes & Related to chitin-binding protein & +187 \\
um05439 & Related to polyketide synthase & +140 \\
um06414 & Conserved hypothetical protein & +121 \\
um06370 & Related to laccase I precursor & +119 \\
um05361 & Related to polyketide synthase & +119 \\
um06418 & Hypothetical protein & +116 \\
um12304 & Hypothetical protein & +103 \\
um03138 & Conserved hypothetical Ustilago-specific protein & +98 \\
um05436 & Putative protein & +69 \\
um02489 & Putative dioxygenase Ssp1 & +68 \\
um12271 & & \\
Downregulated genes & Hmp1; cruciform DNA recognition protein Hmp1 & \\
um00496 & Conserved hypothetical protein & \\
um11020 & Conserved hypothetical protein & -378 \\
um02416 & Mfa1; mating factor a1 & -152 \\
um02382 & Probable ENA2' P-type ATPase & -95 \\
um12056 & Conserved hypothetical protein & -94 \\
um04482 & Conserved hypothetical protein & -62 \\
um02161 & Conserved hypothetical protein & -52 \\
um01187 & Related to opsin-1 & -45 \\
um00371 & Conserved hypothetical protein & -38 \\
um05325 & -38 & -36 \\
\hline
\end{tabular}

\footnotetext{
${ }^{\mathrm{z}}$ Representative fold change from three biological replications.
} 
cosmids containing full-length WT lacl or pksl alleles, respectively, were also included in this analysis. Under these conditions, pigment production was induced and cultures of parental strain SG200 became moderately dark, whereas this pigmentation was reduced in the $\Delta l a c l$ strain and fully abolished in the $\Delta p k s 1$ strain (Fig. 5A). Reintroduction of the lacl or $p k s 1$ genes restored cell pigmentation to near-WT and WT levels, respectively (Fig. 5A). Cells from these cultures were
A

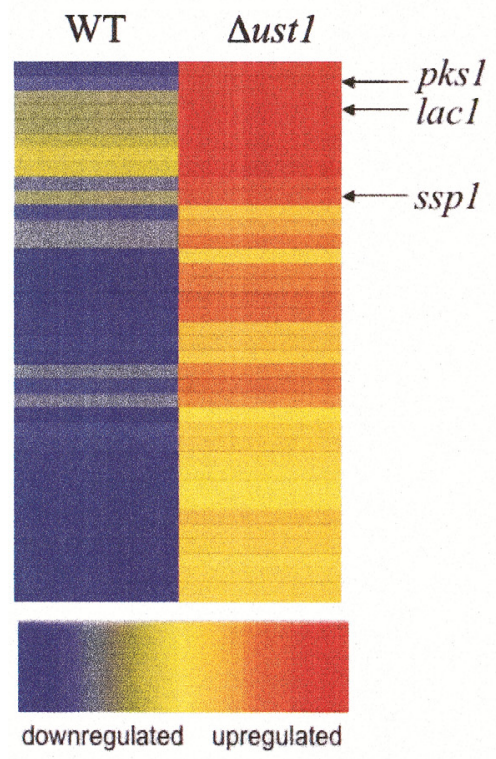

B

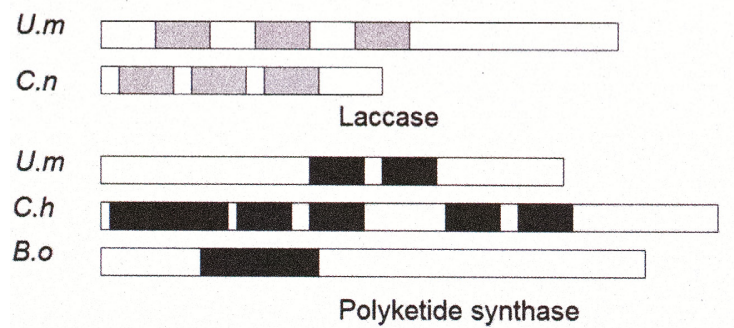

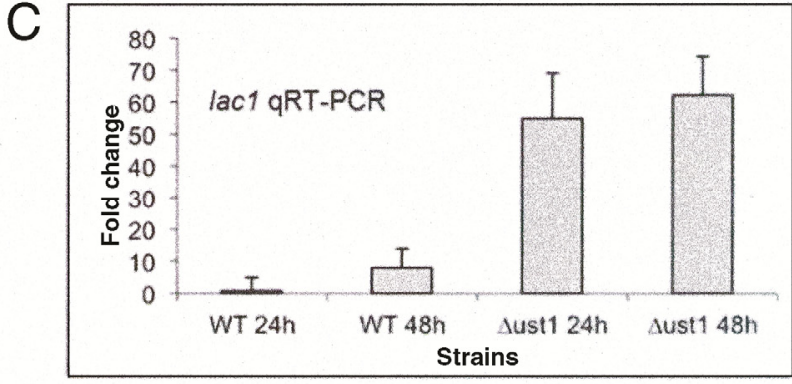
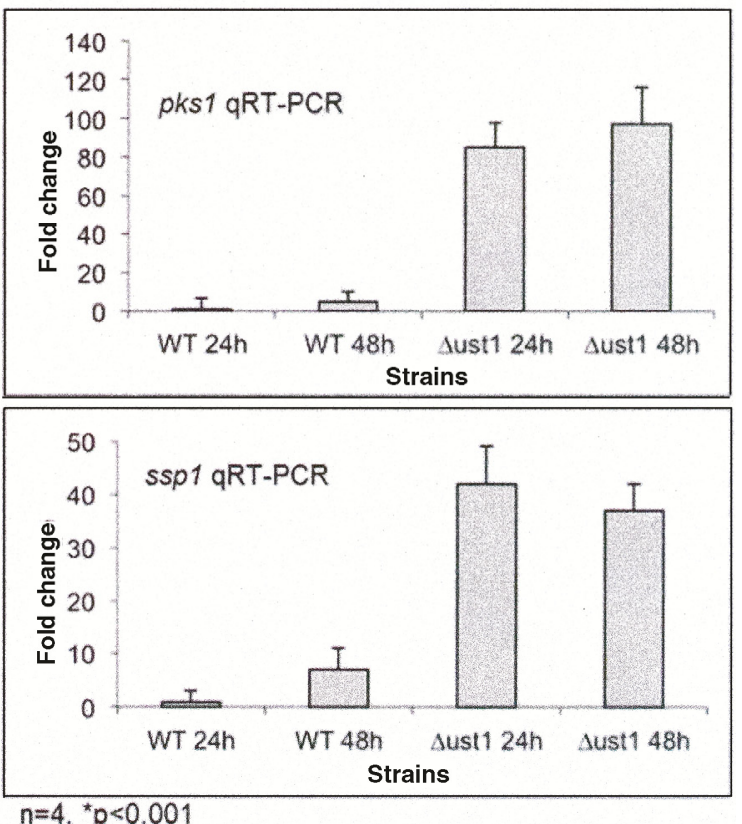

$n=4,{ }^{*} p<0.001$

Fig. 3. Expression analysis and functional domains of $l a c 1$ and $p k s 1$. A, Heat map of microarray gene expression data. The relative fold change in expression levels of the $36>20$-fold upregulated genes in the $\Delta u s t 1$ mutant strain is compared with the wild-type (WT) strain $1 / 2$ at 48 h. Microarray data show the average of three biological replicates. Fold changes are indicated by increasing color saturation, with bright red denoting highest upregulated fold change. Sporespecific protein 1 gene (sspl), upregulated in mature teliospores (Huber et al. 2002), is highly upregulated in the $\Delta u s t 1$ mutant strain (arrow). Two enzymeencoding genes typically involved in secondary metabolism, laccase 1 (lacl) and polyketide synthase 1 (pks 1 ), are also upregulated in the $\Delta u s t 1$ mutant strain (arrows). B, Comparison of positioning of laccase (multicopper oxidase) domains in Ustilago maydis (U.m) lac1 (um05361) and laccase 1 (CNLAC1) from Cryptococcus neoformans (C.n) (gray boxes) and comparison of positioning of polyketide synthase domains in U. maydis pks1 (um06414), Colletotrichum heterostrophus (C.h) pksl, and Bipolaris oryzae (B.o) pksl (black boxes). C, Validation of differential expression by quantitative real-time polymerase chain reaction (qRT-PCR)PCR of lacl, pksl, and sspl in $\Delta u s t l$ compared with the WT after $48 \mathrm{~h}$ of growth in potato dextrose broth. Fold change was calculated with the $2^{-\Delta \Delta C T}$ method (Applied Biosystems) and in relation to the constitutively expressed ppi gene. Shown here are the mean values and standard error of four biological replicates.

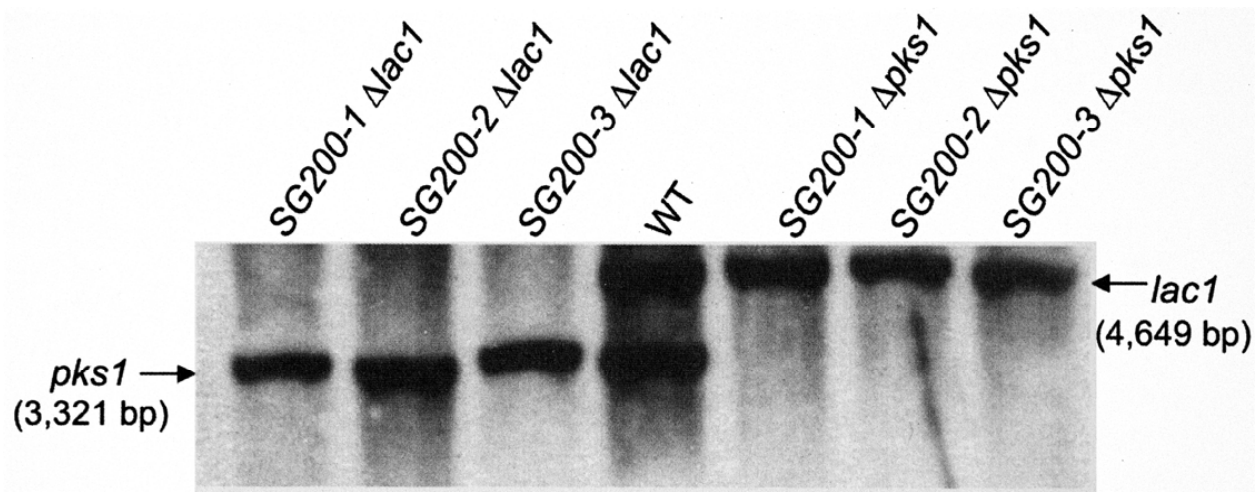

Fig. 4. Multiplex Southern blot confirmation of deletion of lacl (um05361) and pks1 (um06414) open reading frames (ORF). Approximately 500 ng of total DNA from each strain was restriction digested with NarI and resolved on a $0.8 \%$ agarose gel. The blot was hybridized to digoxigenin-labeled ORF probes according to the manufacture's protocol. 
centrifuged and it was noted that the supernatant remained clear, whereas pellets of parental WT SG200 were dark, indicating pigment retention within the cell walls (Fig. 5B). When observed microscopically, cells from these cultures exhibited aberrant morphology even in the case of WT SG200. However, whereas SG200 had darkly pigmented cell walls, SG200 $\Delta p k s 1$ cell walls remained hyaline (Fig. 5C).
Gene lac1 but not pks1 plays a dramatic role in seedling virulence.

The role of lacl and pksl in virulence to maize was analyzed. We first performed pathogenicity assays on 7-day-old maize seedlings and observed that deletion of lacl resulted in severely reduced disease symptoms. Thus, whereas, after 14 days, many plants infected with SG200 had formed galls,
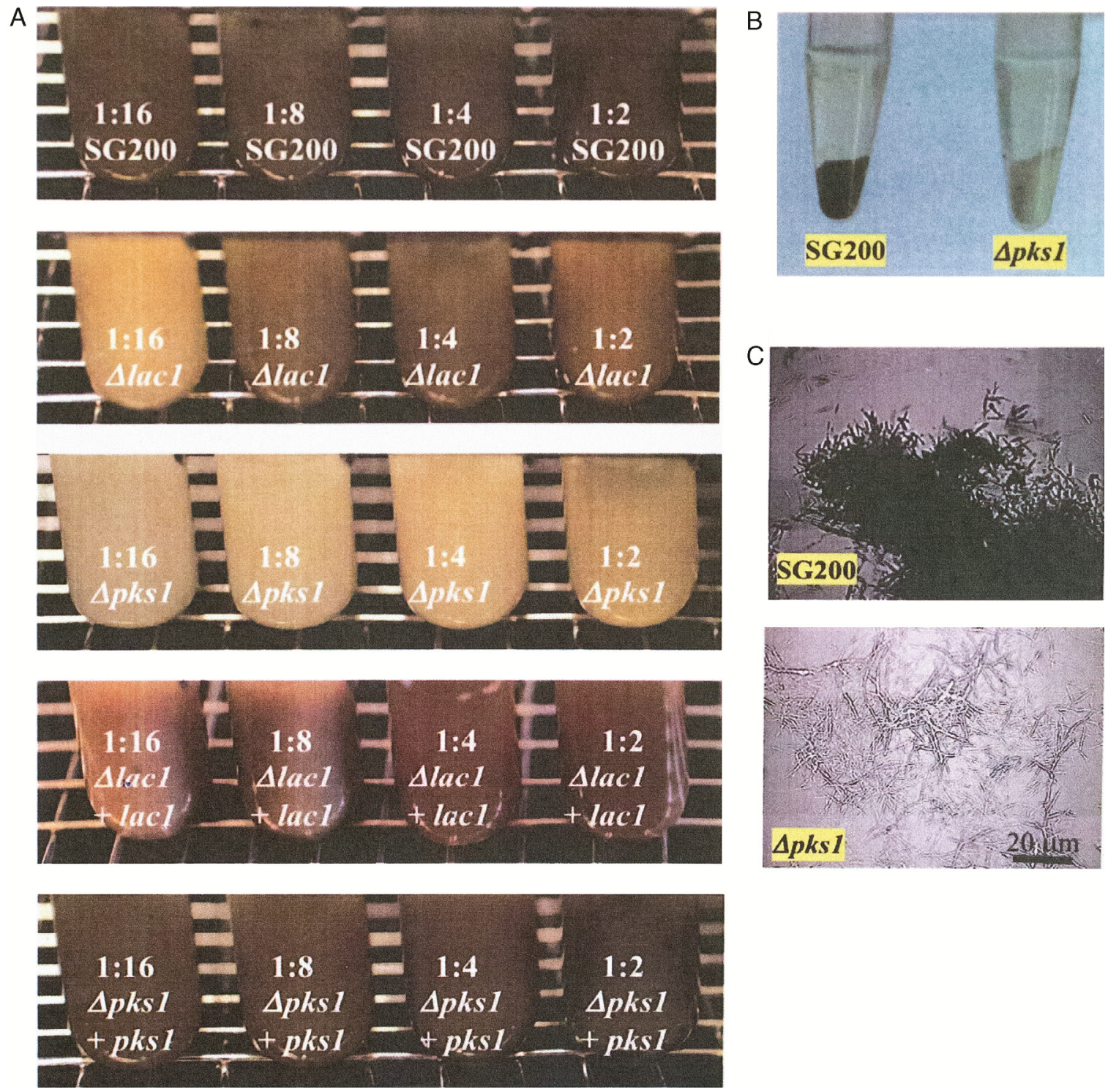

Fig. 5. Effects of $l a c l$ and $p k s 1$ genes on in vitro stress-induced cell pigmentation. A, Parental strain (SG200), mutant strain $\Delta l a c l$, mutant strain $\Delta p k s 1$, lacl mutant complemented with a lac 1 containing cosmid $(\Delta l a c 1+l a c 1)$, and $p k s 1$ mutant complemented with a pks 1 containing cosmid $(\Delta p k s 1+p k s 1)$ were grown in yeast extract-peptone-sucrose at $30^{\circ} \mathrm{C}$ until mid- to late-logarithmic phase optical density of 3 to 6.4 ), then transferred to potato dextrose broth at $1: 2,1: 4,1: 8$, and $1: 16$ dilutions and incubated for $96 \mathrm{~h}$ at $34^{\circ} \mathrm{C}$. B, Centrifuged cell cultures of SG200 and $\Delta p k s 1$. C, Microscopic view of pigmentation of SG200 and $\Delta p k s 1$ cells.

Table 3. $\Delta$ lacl pathogenicity at 14 days postinoculation ${ }^{\mathrm{y}}$

\begin{tabular}{|c|c|c|c|c|c|c|c|c|}
\hline Strains & Number of plants & $\mathbf{0}$ & 1 & 2 & 3 & 4 & 5 & Rating $^{\mathbf{z}}$ \\
\hline SG200 & 25 & 1 & 10 & 2 & 3 & 8 & 1 & $2.40 \mathrm{a}$ \\
\hline SG200-1 $\Delta l a c 1$ & 31 & 17 & 14 & 0 & 0 & 0 & 0 & $0.45 \mathrm{~b}$ \\
\hline SG200-2 $\Delta l a c 1$ & 35 & 19 & 16 & 0 & 0 & 0 & 0 & $0.46 \mathrm{~b}$ \\
\hline SG200-3 $\Delta l a c 1$ & 34 & 18 & 16 & 0 & 0 & 0 & 0 & $0.47 \mathrm{~b}$ \\
\hline Noninoculated & 23 & 20 & 3 & 0 & 0 & 0 & 0 & $0.13 \mathrm{~b}$ \\
\hline
\end{tabular}

${ }^{\mathrm{y}}$ These results correspond to one representative pathogenicity experiment. Similar results were obtained in three independent experiments. The disease ratings are as follows: $0=$ no symptoms, $1=$ anthocyanin or chlorosis, $2=$ small leaf galls, $3=$ small stem galls, $4=$ basal stem galls, and $5=$ plant death SG200-1 $\Delta l a c 1$, SG200-2 $\Delta l a c 1$, and SG200-3 $\Delta l a c 1$ are three independently generated lacl deletion mutants.

${ }^{\mathrm{z}}$ Values followed by different letters are significantly different $(P \leq 0.05)$ in Duncan's multiple range test. 
Slacl strains primarily generated chlorosis and, dramatically, produced no galls (Table 3 ). In contrast, deletion of pks 1 did not lead to a reduction in disease severity to seedlings (Table 4).

\section{Genes lac1 and pks1 play minor and major roles,} respectively, in teliospore pigmentation in adult ears.

To more closely examine the role of lacl and pksl in genuine teliospore development, developing maize ears in adult plants were inoculated. Infected ears were examined 21 days postinoculation to analyze spore development. Both mutants induced extensive tumors comparable with those produced by the WT (Fig. 6). However, the quantity and pigment intensity of teliospores was reduced in galls infected with the $\Delta l a c 1 \mathrm{mu}-$ tant and, strikingly, teliospore pigmentation was completely absent in the galls from plants infected with the $\Delta p k s 1$ mutant.

\section{DISCUSSION}

Our knowledge of molecular signaling underlying teliospore development in $U$. maydis is modest, hindered by the impossibility of inducing this process outside the host plant. In this work, we took advantage of a $\Delta u s t l$ strain which, in culture, develops rounded and darkly pigmented structures resembling teliospores produced in plant galls (García-Pedrajas et al. 2010) to gain new insights into the regulation of this process. Employing a custom microarray, we identified several hundred genes that were differentially expressed when comparing $\Delta u s t 1$ and WT 48-h in vitro cultures. We identified 808 more than twofold differentially expressed genes, 184 of which had more than eightfold change. Of these 184 genes, 111 genes were upregulated and 73 downregulated in the $\Delta u s t 1$ strain. Of the 111

Table 4. $\Delta p k s 1$ pathogenicity at 14 days postinoculation ${ }^{\mathrm{y}}$

\begin{tabular}{|c|c|c|c|c|c|c|c|c|}
\hline Strains & Number of plants & $\mathbf{0}$ & 1 & 2 & 3 & 4 & 5 & Rating $^{z}$ \\
\hline SG200 & 38 & 6 & 5 & 21 & 4 & 2 & 0 & $1.76 \mathrm{ab}$ \\
\hline SG200-1 $\Delta p k s 1$ & 41 & 3 & 12 & 15 & 9 & 2 & 0 & $1.87 \mathrm{ab}$ \\
\hline SG200-2 $\Delta p k s 1$ & 42 & 0 & 15 & 21 & 5 & 1 & 0 & $1.80 \mathrm{ab}$ \\
\hline SG200-3 $\Delta p k s 1$ & 37 & 0 & 5 & 16 & 12 & 4 & 0 & $2.40 \mathrm{a}$ \\
\hline Noninoculated & 34 & 18 & 16 & 0 & 0 & 0 & 0 & $0.47 \mathrm{~b}$ \\
\hline
\end{tabular}

${ }^{y}$ Results from one representative pathogenicity test. Similar results were obtained in three independent experiments. SG200-1 $\Delta p k s 1$, SG200-2 $\Delta p k s 1$, and SG200-3 $\Delta p k s 1$ are three independently generated $p k s 1$ deletion mutants.

${ }^{\mathrm{z}}$ Values followed by different letters in the rating column are significantly different $(P \leq 0.05)$ in Duncan's multiple range test.
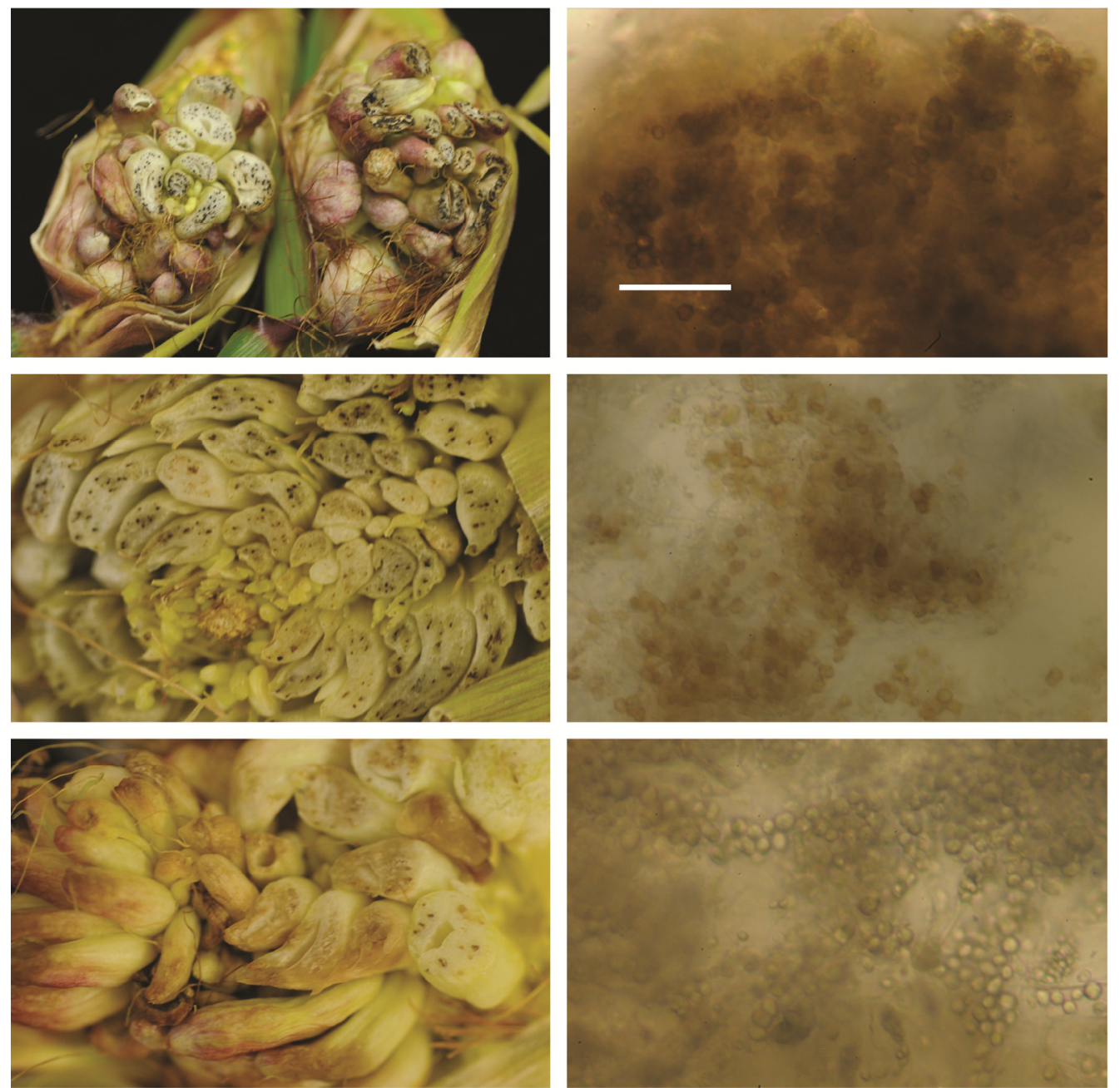

Fig. 6. Teliospore development in maize galls induced by the wild-type (WT), $\Delta l a c 1$, and $\Delta p k s 1$ mutant strains. Tumors (left) induced by the WT, $\Delta l a c 1$ (LAC), and $\Delta p k s 1$ (PKS) mutant strains were photographed 22 days after inoculation. Teliospore production and pigmentation (right) are shown in handsectioned specimens derived for the pictured galls. 
upregulated genes, 36 genes were $>20$-fold upregulated during the filamentation or sporogenesis phase. A gene previously reported as highly expressed in teliospores (Huber et al. 2002), sspl, was in the group of genes we identified as highly induced during production of the spore-like structures by the $\Delta u s t 1 \mathrm{mu}-$ tant. As noted in the Results, other genes upregulated in $\Delta u s t 1$ versus WT (e.g., um05361, um06418, um02035, and um03522) exhibited homology to genes in other fungal species involved in spore development or pigmentation. This result indicated that the spore-like structures produced by the $\Delta u s t 1$ mutant in culture share developmental features with genuine fungal spores. To further explore the roles these genes played in teliosporogenesis or pigmentation, here, we functionally characterized two of the identified highly upregulated genes. For this functional analysis, we focused on laccase (lacl, um05361) and PKS (pks1, um06414), upregulated 119- and 140-fold, respectively, compared with the WT. Bölker and associates (2008) identified three putative PKS-encoding genes in the $U$. maydis genome. The nearby highly induced pks-related gene, um06418 (upregulated 119-fold) (Table 2), was not a target of functional analysis in this study, in part because of the dramatic null pigmentation phenotype obtained with the single pksl (um06414) deletion. A third identified PKS (um04105) (Bölker et al. 2008) was not induced in the ust 1 deletion mutant. Although a member of the Basidiomycota like Cryptococcus neoformans, the fact that pksl appears to play the predominant role in melanin biosynthesis indicates that, unlike its relative, $U$. maydis is not restricted to production of L-DOPA-derived melanin. It is possible that lacl could play a role in this pathway by polymerizing the DHN melanin subunits synthesized by $p k s 1$ activity into melanin, as has been suggested for melanin biosynthetic clusters in which both PKS and laccase enzymes are present (Eisenman and Casadevall 2012). However, lacl is unlinked to pksl and, thus, could potentially be involved in L-DOPAderived melanin. Both DHN and L-DOPA melanin pathways are found in many fungi. The presence of catechol melanin (AKA plant melanin) reported by early biochemical characterization in U. maydis (Piattelli et al. 1963) is not supported by our results. This type of melanin is reportedly synthesized through the activity of polyphenol oxidase enzymes potentially using dopamine as a substrate. Our finding that the $\Delta p k s 1$ mutant was essentially devoid of spore pigmentation suggests that $U$. maydis depends on DHN melanin production and that there are not alternative pathways that mask the effects of this deletion. Thus, we propose that lacl plays a relatively minor role in pigmentation but depends on production of substrate through pks1 via the DHN melanin pathway, as has been reported for several fungi of the phylum Ascomycota, including plant pathogens (Lin et al. 2012; Sugareva et al. 2006). However, some DHN pathway enzymatic functions are not detected in the $U$. maydis genome, including hydroxynaphthalene dehydratase and scytalone dehydratase (Langfelder et al. 2003). Although not tested here, we speculate that deletion of the linked PKS (um06418) would generate a phenotype similar to that of $\Delta p k s l$. As noted by Bölker and colleagues (2008), the proteins encoded by um06414 and um06418 together but not individually possess all necessary PKS functional domains and, thus, would be expected to act by complementary gene action.

In this work, we characterized a gene with a potential role in melanin synthesis, lacl (um05361), highly similar to other fungal laccase genes. As discussed above, a few fungi synthesize melanin via a pathway utilizing L-DOPA as substrate. In this pathway, L-DOPA is oxidized by laccase and then polymerized into melanin (Eisenman et al. 2007). That is the case of $C$. neoformans, where laccase is a cell wall-associated virulence factor and functions in melanin biosynthesis of the spore wall (Zhu and Williamson 2004). CNLAC1 and CNLAC2 are the only two apparent laccase genes in $C$. neoformans. They are $5.3 \mathrm{~kb}$ apart in the same orientation, with $72 \%$ amino acid sequence identity. However, only deletion of CNLACl generated nonmelanized mutants (Zhu and Williamson 2004). In the $U$. maydis genome, there are also two laccase genes, um05361 (lac1) and um05861 (lac2), which are not linked; however, both were highly upregulated in $\Delta u s t 1$ (119- and 48-fold, respectively). We deleted lacl, which is more similar to CNLAC1 than to CNLAC2, in the solopathogenic strain SG200 and observed that the $\Delta l a c l$ mutant strain induced galls with a reduced number of teliospores and reduced teliospore pigmentation, whereas WT SG200-generated galls contained abundant melanized teliospores. Because melanin production in $C$. neoformans requires laccase (Eisenman et al. 2007), a similar phenomenon may operate in $U$. maydis because both are members of the phylum Basidiomycota. However, although laccases play a critical role in the synthesis of melanin via L-DOPA, they or similar multicopper oxidases could also play a role in the synthesis of DHN melanin. For example, the gene cluster for conidial pigment biosynthesis in A. fumigatus in addition to PKS (alb1), SCD (arpl), and THN-reductase (arp2) genes also contains a multicopper oxidase $(a b r l)$ and a laccase gene (abr2) (Tsai et al. 1999). Interestingly, in seedlings but not adult plants, virulence was reduced in $\Delta l a c l$ mutant strains. However, tumors induced by the $\Delta l a c l$ mutant in ears contained fewer and less darkly pigmented teliospores compared with the WT. Although not tested here, we speculate that deletion of both lacl and lac2 might have a more dramatic effect on teliospore pigmentation. Lac1 likely has a function of extracellular lignin degradation and, because Lac1 has a 23-aminoacid signal peptide typical of extracellular enzymes, it is likely that laccase is secreted following infection in order to degrade the plant cell wall, of which $5 \%$ is lignin (Marita et al. 2003), and allow fungal invasion. The differential effects on seedlings versus adult plants of the $\Delta l a c l$ mutant potentially could be due to differential induction in these tissues, as was reported for many $U$. maydis genes (Skibbe et al. 2010). Alternatively, and perhaps more likely, seedlings contain more lignin than developing ovaries and, thus, the fungus requires laccase for cell wall breakdown in order to efficiently colonize these structures but not to produce ear galls.

In this work, we also examined the role of $p k s l$ by analysis of deletion mutants. The roles in virulence of PKS genes in different fungal species vary. In some animal pathogens, melanization appears to contribute to virulence by reducing the susceptibility of melanized fungal structures to host defense mechanisms and antifungal drugs. For example, in A. fumigatus, mutants deficient for the PKS, PksP, produce white conidia instead of the gray-green conidia typical of the WT and are strongly attenuated in virulence in a mouse model (Langfelder et al. 2001). Another similar case is Penicillium marneffei, in which deletion of the PKS gene albl leads to the lack of melanin and reduced ornamentation in conidia and reduced virulence toward mice (Woo et al. 2010). In plant pathogens that produce highly differentiated melanized appressoria to penetrate plant tissue such as $M$. oryzae, deletion of its respective melanin synthetic PKS gene generated nonmelanized appressoria incapable of penetrating rice leaves (Oh et al. 2008). Appressoria of $U$. maydis, on the other hand, are weakly differentiated and nonmelanized. In this species, the role of $p k s 1$ appears to be restricted to melanin synthesis because we did not detect any role in pathogenic development. Our analysis of the pksl promoter by using the Kyoto University Bioinformatics Center network database (GenomeNet) identified two StuA consensus-fitting binding sites, 10 bp per site: CAACGCGCTT at $207 \mathrm{bp}$ and CATCGCGAAT at $350 \mathrm{bp}$ upstream of the $p k s 1$ 
ORF. Because the DNA-binding domain (APSES domain) of StuA from A. nidulans is $70.1 \%$ identical to APSES domain of Ust1 from $U$. maydis (García-Pedrajas et al. 2010), we predicted that Ust1 may directly bind StuA sites in the pks 1 promoter. Our data are consistent with the prediction that Ust1 is a transcriptional repressor of genes induced during teliosporogenesis in U. maydis (García-Pedrajas et al. 2010). Consistent with this hypothesis, in microarray experiments not reported here, we found that $u$ st 1 was downregulated 1.97-fold in late, actively sporulating galls (21 days postinoculation) versus early (14 days postinoculation) galls (E. Islamovic, unpublished results). In the absence of Ust 1 , repression is abolished and genes induced during teliosporogenesis are upregulated, such as the $p k s 1$ gene. However, in recent work, we did not find evidence that Ust1 binds the canonical StuA response elements in vitro (Baeza-Montañez et al. 2015) and, therefore, we are uncertain whether the regulation of these genes involved in melanin synthesis by ustl is direct or indirect.

Transcript levels of the genes previously shown to be involved in development leading to teliospore formation varied in our microarray experiments (Fig. 7). During teliospore-like structure formation and teliospore development, transcript levels of hdal (um02065) and gpa3 (um04474) increased, while transcript levels of fuzl (um02587) and ruml (um02582) decreased. In this study, we characterized two genes involved in teliospore development in $U$. maydis and we propose their possible genetic temporal involvement during teliosporogenesis (Fig. 8). This development begins with the filamentous pathogenic dikaryon located inside a maize gall undergoing extensive morphological alterations such as filament fragmentation and cell wall thickening to produce round, dark teliospores (Banuett and Herskowitz 1996; Snetselaar and Mims 1994). Genes shown to play developmental roles leading to teliosporogenesis are hdal (um02065), gpa3 (um04474), fuzl (um02587), ruml (um02582), and hgll (um11450). Mutation of each gene results in arrest in teliospore development at a specific stage. The $\Delta h d a l$ deletion mutant, the gpa $3_{\mathrm{Q} 206 \mathrm{~L}}$ constitutively active mutant, and $\Delta f u z l$ inactivation mutant are all arrested after branching but prior to filament fragmentation (Banuett and Herskowitz 1996; Kruger et al. 2000; Reichmann et al. 2002). The $\Delta r u m 1$ deletion mutant is arrested after filament fragmentation but prior to spore structure formation (Quadbeck-Seeger et al. 2000). The $\Delta u s t 1$ mutant itself does not release its spore-like structures from the mycelium, which is superficially consistent with downregulation of fuzl and ruml. The $\Delta h g l l$ deletion mutant is arrested after hyphal fragmentation and produced only a few hyaline, rounded structures reminiscent of immature teliospores (Durrenberger et al. 2001). Our results suggest that both $\Delta l a c l$ and $\Delta p k s 1$ deletion mutants are arrested at a late spore developmental stage where teliospores have developed but are not fully mature. The hgll mutant phenotype suggests that it may be immediately upstream and a potential regulator of lacl and pksl. Our microarray experiments in plant galls in an hgll deletion mutant showed significant decrease in both lacl (257-fold) and pksl (11-fold) expression compared with the WT (data not shown), which is consistent with an upstream requirement for and potential regulation by $h g l l$.

In summary, this work has provided evidence that the in vitro "sporulation" phenotype of the $\Delta u s t 1$ mutant is related to in planta teliosporogenesis. Through functional analysis of two genes highly upregulated in the ust 1 mutant, we made key insights into their roles in melanin biosynthesis both in vitro and in planta in $U$. maydis. Additionally, distinctly different effects were observed for lacl and pksl mutants. Mutant lacl plays a relatively weak role in pigmentation but a significant role in virulence in seedlings. On the other hand, $p k s 1$ appears to play no role in virulence but is required for teliospore pigmentation. This suggests that, unlike its fellow Basidiomycota relative, $C$. neoformans, $U$. maydis employs a modified DHN pathway for spore melanization. Additionally, the deposited

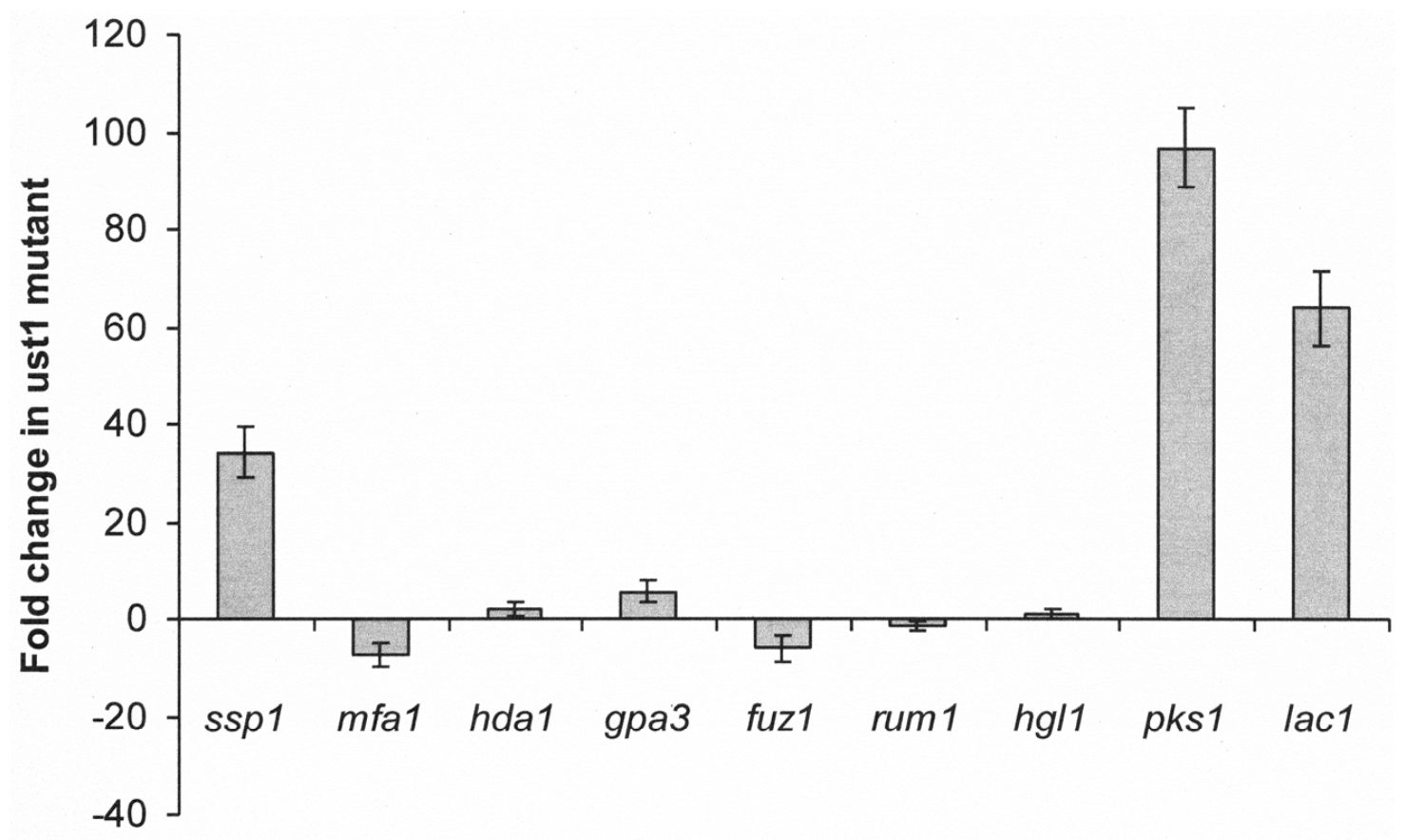

\section{Sporulation genes}

Fig. 7. Relative fold change of sporulation related genes in the $\Delta u s t 1$ mutant compared with the wild type at $48 \mathrm{~h}$ in vitro via microarray. Identified proteins involved in tumor/spore development are: Ssp1 (um12271), Mfa1 (um02382), Hda1 (um02065), Gpa3 (um04474), Fuz1 (um02587), Rum1 (um02582), Hgl1 (um11450), Pks1 (um06414), and Lac1 (um05361). Data are from three biological replicates. 
array data provide hundreds of additional candidate genes for further exploration of sporogenesis in $U$. maydis.

\section{MATERIALS AND METHODS}

Fungal strains and growth conditions.

The U. maydis strains used in this study are presented in Table 1. Standard growth of fungal strains was at $30^{\circ} \mathrm{C}$ on potato dextrose agar (PDA) (Sigma-Aldrich, St. Louis) plates supplemented to $2 \%$ agar (2PDA) or in PDB with shaking at $200 \mathrm{rpm}$. Cultures used for protoplast generation were grown in YEPS medium (1\% yeast extract, $2 \%$ peptone, and $2 \%$ sucrose) and transformants plated on YEPS containing $2 \%$ agar supplemented with $1 \mathrm{M}$ sorbitol and carboxin at $3 \mu \mathrm{g} / \mathrm{ml}$ for selection. Array medium and other specialized media used for specific purposes are described in the pertinent sections below.

\section{Microarray analysis and}

qPCR differential expression confirmation.

To identify genes potentially involved in the sporulation program, we carried out microarray analysis comparing a haploid U. maydis WT strain (1/2) and $\Delta$ ustl (14/25) in vitro. Two types of microarray chips (1-plex and 4-plex) containing 6,869 $U$. maydis ORF were designed, produced, and validated by NimbleGen Systems, Inc. (Madison, WI) using the genome sequence of $U$. maydis publicly available at the MIPS $U$. maydis Genome Database. We generated three biological replicates (A, B, and C). For samples from groups A and B, a 1-plex NimbleGen microarray chip was used (manufacturer's website). On the 1-plex chip, each U. maydis gene was represented by 14 different probes spread throughout each gene. This was replicated in four blocks (four technical reps per chip). For samples from group $\mathrm{C}$, a 4-plex NimbleGen microarray chip was used. On the 4-plex chip, each $U$. maydis gene was probed using 10 different probes. Averages were taken from the probe sets and reported as expression values. WT and $\Delta u s t l$ strains were grown in PDB for $48 \mathrm{~h}$ at $30^{\circ} \mathrm{C}$. To allow effective comparison with other array data generated by $U$. maydis research- ers, cells were then transferred to liquid array medium $(6.25 \%$ Holiday salt solution, $30 \mathrm{mM}$ L-glutamine, and $1 \%$ glucose [pH 7.0] and filter sterilized) at $30^{\circ} \mathrm{C}$ (Scherer et al. 2006). Total RNA samples from WT $1 / 2$ and $\Delta u s t 1$ mutant strains grown in array medium for $24 \mathrm{~h}$ (mutant's filamentous phase) and 48 h (mutant's teliospore-like structure formation phase) were extracted and purified (Sigma Spectrum plant total RNA kit, catalog number STRN50). RNA was sent to NimbleGen, where it was reverse transcribed to cDNA and Cy3 labeled. The cDNA samples were hybridized to custom one color arrays, microarray chips were scanned, and raw data were normalized with appropriate controls and statistically analyzed using standard NimbleGen microarray pipeline. Gene expression patterns were visualized as a scatter plot using ArrayStar v2.0 software. The entire set of supporting microarray data is deposited at Gene Expression Omnibus (accession number GSE54659).

For qPCR, total RNA was extracted from WT and $\Delta u s t 1$ strains grown for 24 and $48 \mathrm{~h}$ in PDB using a Spectrum plant total RNA kit (Sigma-Aldrich). cDNA was synthesized using the SuperScript III first-strand synthesis system for qPCR (Invitrogen, Carlsbad, CA) using oligo-dT priming and according to the manufacturer's recommendations. Transcript abundance was quantified by qPCR using SYBR-GREEN methodology (Bio-Rad, Hercules, CA) with gene-specific primers designed through the Integrated DNA Technologies website. Reactions were performed on a Cepheid SmartCycler I (Cepheid, Sunnyvale, CA). Transcript relative expression levels for lacl, $p k s 1$, and sspl were calculated by using $\Delta$ cycle threshold (CT) calculations $\left(2^{-\Delta \Delta C T}\right.$ method) (Pfaffl 2001) with primer pairs lac1qPCRf and lac1qPCRr; pks1qPCRf and pks1qPCRr; ssp1qPCRf and ssp1qPCRr; and normalized to a reference cyclophilin gene, ppi (um03726) using primers ppif and ppir (Table 5), as previously described (Doehlemann et al. 2009). Means of gene expression fold-changes and their corresponding standard error were calculated based on four biological replicates. Comparisons were made regarding positioning of laccase (multicopper oxidase) domains in $U$. maydis lacl (um05361) and laccase 1 (CNLAC1) from C. neoformans (Zhu

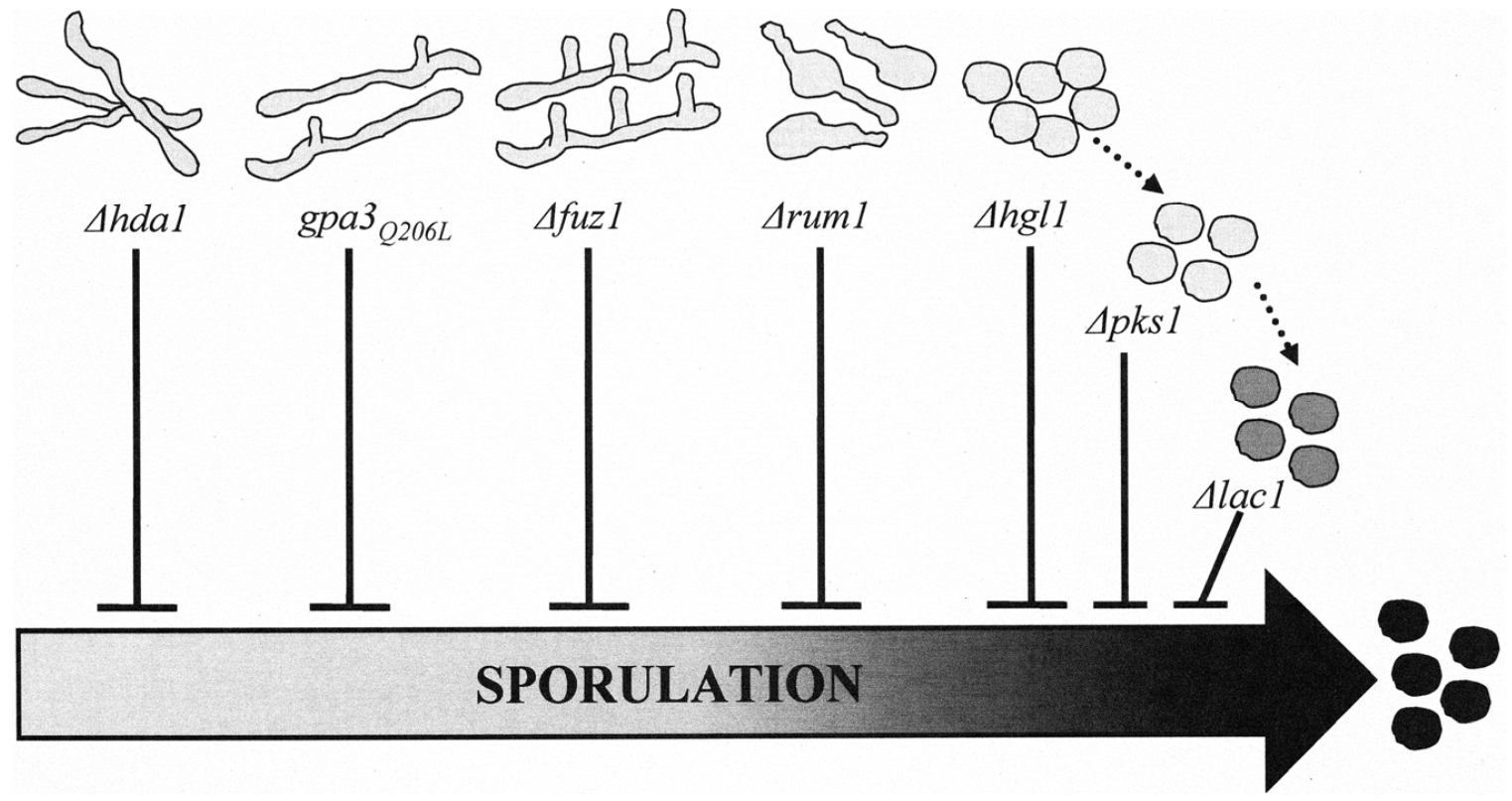

Fig. 8. Positioning of lacl and pks1 in a temporal model of gene function affecting Ustilago maydis teliosporogenesis. Identified genes involved in teliosporogenesis are hdal (um02065) (Reichmann et al. 2002), gpa3 (um04474) (Kruger et al. 2000), fuz1 (um02587) (Banuett and Herskowitz 1996), rum1 (um02582) (Quadbeck-Seeger et al. 2000), and hgll (um11450) (Durrenberger et al. 2001). Mutation of each gene results in arrest in teliospore development. The $\Delta$ hdal deletion mutant, gpa $3_{\mathrm{Q} 206 \mathrm{~L}}$ constitutively active mutant, and $\Delta$ fuzl inactivation mutant are all arrested after branching but prior to filament fragmentation. The $\Delta r u m l$ and $\Delta h g l l$ deletion mutants are arrested after filament fragmentation but prior to spore structure formation. Our results suggest that $\Delta l a c l$ and $\Delta p k s 1$ mutants are defective in late spore development. 
and Williamson 2004) and comparison of positioning of PKS domains in U. maydis pks1 (um06414), Colletotrichum heterostrophus pks1 (GenBank: U68040.3) (Baker et al. 2006), and B. oryzae pksl (GenBank: AB176546.1) (Moriwaki et al. 2004).

\section{Production and complementation}

\section{of lac1 and pks 1 deletion mutants.}

The lacl and pks1 deletion constructs were prepared using the DelsGate method (García-Pedrajas et al. 2008) with the gene-specific "DGP" primers (Table 5). For lacl gene deletion, Lac1DGP1/Lac1DGP2 and Lac1DGP3/Lac1DGP4 primer pairs were used whereas, for $p k s 1$ gene deletion, Pks1DGP1/ Pks1DGP2 and Pks1DGP3/Pks1DGP4 primer pairs were used to amplify the $5^{\prime}$ and $3^{\prime}$ gene flanks, respectively. Escherichia coli DH5 $\alpha$ cells were used for transformation during deletion construct assembly. Low-sodium Luria-Bertani medium containing kanamycin (Research Products International Corp., Chicago) at $50 \mu \mathrm{g} / \mathrm{ml}$ was used for selecting E. coli transformants. U. maydis transformations were performed using a protocol from Tsukuda and associates (1988), with modification in protoplast generation. For these experiments, we replaced Novozyme 234, which is no longer available, with Vinoflow enzyme (Novozymes, Denmark). The absence of the lacl or pksl ORF was first confirmed via PCR by using primers lac1F/ lac1R or pks1F/pks1R, respectively (Table 5). Transformants with no amplification product were subsequently screened for homologous integration of the deletion construct via PCR using primers lac1 $5 / \mathrm{cbx}$ out or pks $15 / \mathrm{cbx}$ out (Table 5). Finally, multiplex Southern blotting was used to confirm that putative transformants indeed lacked bands hybridizing to the ORF of um05361 or um06414. Approximately $500 \mathrm{ng}$ of total DNA from each strain was restriction digested with NarI and resolved on a $0.8 \%$ agarose gel. The gel was stained with ethidium bromide and relative band size versus migration distance was documented with a HindIII-digested $\lambda$ DNA marker, followed by alkaline transfer to a Hybond XL membrane (Amersham Pharmacia Biotech, UK). The blot was prehybridized for approximately $4 \mathrm{~h}$ at $42^{\circ} \mathrm{C}$ followed by simultaneously probing overnight with ORF fragments of both um05361 (889 bp) and um06414 (725 bp). The probes were generated by PCR amplification using primers lac $1 \mathrm{~F}$ and lac1R and pks $1 \mathrm{~F}$ and pks1R, respectively (Table 5), labeled with digoxigenindUTP using the DIG-high prime kit, and added together at a concentration of $25 \mathrm{ng} / \mathrm{ml}$ each, with washing and detection steps according to the protocol specified by the manufacturer (Roche, Branchburg, NJ, U.S.A.).

Deletion mutants complemented with lacl or pksl genes were also generated. For that, mutant strains (Table 1) were transformed with cosmids from a WT strain $1 / 2 \mathrm{U}$. maydis library constructed in the autonomously replicating cosmid vector pJW42 (Barrett et al. 1993) containing the lacl or pksl gene, respectively. Cosmids from the library harboring fulllength genes were identified as described previously (Smith et al. 2004) with primers Lac1DGP1 and Lac1DGP4 or Pks1DGP1 and Pks1DGP4. For complementation, $\Delta l a c 1$ and $\Delta p k s 1$ deletion mutant protoplasts were generated and transformed with the appropriate cosmid. Transformants were selected with hygromycin at $150 \mu \mathrm{g} / \mathrm{ml}$ for cosmid selection and transferred to PDA plates amended with carboxin at $3 \mu \mathrm{g} / \mathrm{ml}$ and hygromycin at $150 \mu \mathrm{g} / \mathrm{ml}$. Complemented transformant strains were cultured in PDB liquid with hygromycin at 50 $\mu \mathrm{g} / \mathrm{ml}$ to ensure retention of complementing cosmids.

\section{Pathogenicity assays and maize ear inoculations.}

Pathogenicity assays were carried out on the susceptible maize 'Golden Bantam' (Rich Farm Garden Supply, Winchester, IN, U.S.A.). Seedlings were inoculated by injection just above the soil line 7 days after planting with a suspension of solopathogenic parental strain SG200 or deletion mutant strains at $1 \times 10^{6}$ cells $/ \mathrm{ml}$ in a SG200 background. Disease symptom data were collected at 7, 10,14, and 21 days after inoculation. Disease ratings were as described previously by Gold and associates (1997). Briefly, symptoms were rated 0 to 5 as follows: $0=$ no disease, $1=$ anthocyanin or chlorosis, $2=$ leaf galls, $3=$ small stem galls, $4=$ large stem galls, and $5=$ plant death . Maize ear inoculations were carried out on the dwarf 'Tom Thumb' (Seed Savers Exchange, Decorah, IA, U.S.A.), as previously described (Chacko and Gold 2012).

\section{Pigment production.}

Pigment production was stress induced in PDB cultures by prolonged incubation at temperatures above normal. First, fungal cells of the WT (SG200), $\Delta l a c l$ strain, $\Delta p k s 1$ strain, lacl deletion mutant complemented with the lacl gene-containing cosmid $(\Delta l a c 1+l a c 1)$, and $p k s 1$ deletion mutant complemented with the $p k s l$ gene-containing cosmid $(\Delta p k s l+p k s l)$

Table 5. Primer sequences used in this study

\begin{tabular}{ll}
\hline Primer ID & \multicolumn{1}{c}{ Primer sequence } \\
\hline Lac1DGP1 & TAGGGATAACAGGGTAATAC AGCATGAAG GTT GTTCCTTGCC \\
Lac1DGP2 & GGGGACAAGTTGTACAAAAAAGCAGGCTAATGTGACAGATCAGACGGCAATCGT \\
Lac1DGP3 & GGGGACCACTTTGTACAAGAAAGCTGGGTAATTCCCGTTGAGTGAAAGCGCAC \\
Lac1DGP4 & ATTACCCTGTTATCCCTAGCAGATTGGTCTTGACGAATGGCA \\
Lac1F & CGGCTTTCTCATGAACGGCAACTT \\
Lac1R & TGATGTGGTAGCCACTTCGGTCAA \\
Lac1 5 & GATGTGGCAACATGTACACTGCCT \\
Pks1DGP1 & TAGGGATAACAGGGTAATAGAGCCCTGTTTGCTCTTCTTCCA \\
Pks1DGP2 & GGGGACAAGTTTGTACAAAAAAGCAGGCTAATCTCAGCTGTGAGCTTGAGCTTCT \\
Pks1DGP3 & GGGGACCACTTTGTACAAGAAAGCTGGGTACTCAACATGCGTCGTGCGTGATTT \\
Pks1DGP4 & ATTACCCTGTTATCCCTAAGGAGTTGGAGTTGATTCAGGCGT \\
Pks1F & TTGACGCAACCTTGCTCACACTTG \\
Pks1R & ACACTGCCTTGCTGAAACATGAGC \\
Pks1 5 & ATATTCACACGCCATGTCGGCTTC \\
cbx out & CGAAAGCGAGACGAGTTG \\
lac1qPCRf & AAATGCAAAGTACGTGGCTCCTGC \\
lac1qPCRr & TGAATGCTCTGAGCGAGTGACCTT \\
pks1qPCRf & GCTCATGTTTCAGCAAGGCAGTGT \\
pks1qPCRr & CACGACTCCATGGCAATTGTGCT \\
ssp1qPCRf & AGCGCCTCTACGAGGTCAATGAAA \\
ssp1qPCRr & TGCAATGCCAAACAGCTCCTCATC \\
ppif & ACGCCGATTCACTTCGTC \\
ppir & AACGACGATCCCTCGTAACCGAAA \\
\hline
\end{tabular}


were grown in $5.0 \mathrm{ml}$ of YEPS at $30^{\circ} \mathrm{C}$ until mid- to latelogarithmic phase (optical density of 3 to 6.4). Then, each strain was transferred at dilutions of 1:2, 1:4, 1:8, and 1:16 with fresh PDB and incubated at $34^{\circ} \mathrm{C}$ for $96 \mathrm{~h}$. Cultures in the glass tubes and pelleted in the Eppendorf tubes were photographed with a Nikon digital camera while fungal cells were photographed as previously described (García-Pedrajas et al. 2010).

\section{ACKNOWLEDGMENTS}

This project was supported by the National Research Initiative of the United States Department of Agriculture Cooperative State Research, Education and Extension Service, grant numbers 2006-35319-16738 to S. E. Gold and S. F. Covert and GEO-2007-01605 to E. Islamovic.

\section{LITERATURE CITED}

Baeza-Montañez, L., Gold, S. E., Espeso, E.,and Garcia-Pedrajas, M. D. 2015. Conserved and distinct functions of the "stunted" (StuA)-homo$\log$ Ust1 during cell differentiation in the corn smut fungus Ustilago maydis. Mol. Plant-Microbe Interact. 28:85-101

Baker, S. E., Kroken, S., Inderbitzin, P., Asvarak, T., Li, B.Y., Shi, L., Yoder, O. C., and Turgeon, B. G. 2006. Two polyketide synthase-encoding genes are required for biosynthesis of the polyketide virulence factor, T-toxin, by Cochliobolus heterostrophus. Mol. Plant-Microbe Interact. 19:139-149.

Banuett F, and Herskowitz, I. 1996. Discrete developmental stages during teliospore formation in the corn smut fungus, Ustilago maydis. Development 122:2965-2976.

Barrett, K. J., Gold, S. E., and Kronstad, J. W. 1993. Identification and complementation of a mutation to constitutive filamentous growth in Ustilago maydis. Mol. Plant-Microbe Interact. 6:274-283.

Bieszke, J. A., Li, L., and Borkovich, K. A. 2007. The fungal opsin gene nop- 1 is negatively-regulated by a component of the blue light sensing pathway and influences conidiation-specific gene expression in Neurospora crassa. Curr. Genet. 52:149-157.

Bölker, M., Genin, S., Lehmler, C., and Kahmann, R. 1995. Genetic regulation of mating and dimorphism in Ustilago maydis. Can. J. Bot. 73:320-325.

Bölker, M., Basse, C. W., and Schirawski, J. 2008. Ustilago maydis secondary metabolism-From genomics to biochemistry. Fungal Genet. Biol. 45:S88-S93.

Chacko, N., and Gold, S. E. 2012. Deletion of the Ustilago maydis ortholog of the Aspergillus sporulation regulator medA affects mating and virulence through pheromone response. Fungal Genet. Biol. 49:426-432.

Christensen, J. J. 1963. Corn smut caused by Ustilago maydis. Am. Phytopathol. Soc. Monogr. 2:41.

Doehlemann, G., van der Linde, K., Assmann, D., Schwammbach, D., Hof, A., Mohanty, A., Jackson, D., and Kahmann, R. 2009. Pep1, a secreted effector protein of Ustilago maydis, is required for successful invasion of plant cells. PLoS Pathog. 5:e1000290.

Durrenberger, F., Laidlaw, R. D., and Kronstad, J. W. 2001. The hgll gene is required for dimorphism and teliospore formation in the fungal pathogen Ustilago maydis. Mol. Microbiol. 41:337-348.

Dutta, S., Gerhold, D. L., Rice, M., Germann, M., and Kmiec, E. B. 1997. The cloning and overexpression of a cruciform binding protein from Ustilago maydis. Biochim. Biophys. Acta Gene Struct. Expr. 1352:258266.

Eisenman, H. C., and Casadevall, A. 2012. Synthesis and assembly of fungal melanin. Appl. Microb. Biot. 93:931-940.

Eisenman, H. C., Mues, M., Weber, S. E., Frases, S., Chaskes, S., Gerfen, G., and Casadevall, A. 2007. Cryptococcus neoformans laccase catalyses melanin synthesis from both D- and L-DOPA. Microbiology 153:3954-3962.

Eisenman, H. C., Frases, S., Nicola, A. M., Rodrigues, M. L., and Casadevall, A. 2009. Vesicle-associated melanization in Cryptococcus neoformans. Microbiology 155:3860-3867.

García-Pedrajas, M. D., Nadal, M., Kapa, L. B., Perlin, M. H., Andrews, D. L., and Gold, S. E. 2008. DelsGate, a robust and rapid gene deletion construction method. Fungal Genet. Biol. 45:379-388.

García-Pedrajas, M. D., Baeza-Montanez, L., and Gold, S. E. 2010. Regulation of Ustilago maydis dimorphism, sporulation, and pathogenic development by a transcription factor with a highly conserved APSES domain. Mol. Plant-Microbe Interact. 23:211-222.

Gold, S. E., Brogdon, S. M., Mayorga, M. E., and Kronstad, J. W. 1997.
The Ustilago maydis regulatory subunit of a cAMP-dependent protein kinase is required for gall formation in maize. Plant Cell 9:15851594.

Holliday, R. 1974. Ustilago maydis. Pages 575-595 in: Handbook of Genetics. R. C. King, ed. Plenum, New York.

Huber, S. M., Lottspeich, F., and Kamper, J. 2002. A gene that encodes a product with similarity to dioxygenases is highly expressed in teliospores of Ustilago maydis. Mol. Genet. Genomics 267:757-771.

Kamper, J., Kahmann, R., Bölker, M., Ma, L.-J., Brefort, T., Saville, B. J., Banuett, F., Kronstad, J. W., Gold, S. E., Muller, O., Perlin, M. H., Wosten, H. A. B., de Vries, R., Ruiz-Herrera, J., Reynaga-Pena, C. G., Snetselaar, K., McCann, M., Perez-Martin, J., Feldbrugge, M., Basse, C. W., Steinberg, G., Ibeas, J. I., Holloman, W., Guzman, P., Farman, M., Stajich, J. E., Sentandreu, R., Gonzalez-Prieto, J. M., Kennell, J. C., Molina, L., Schirawski, J., Mendoza-Mendoza, A., Greilinger, D., Munch, K., Rossel, N., Scherer, M., Vranes, M., Ladendorf, O., Vincon, V., Fuchs, U., Sandrock, B., Meng, S., Ho, E. C. H., Cahill, M. J., Boyce, K. J., Klose, J., Klosterman, S. J., Deelstra, H. J., Ortiz-Castellanos, L., Li, W., Sanchez-Alonso, P., Schreier. P. H., Hauser-Hahn, I., Vaupel, M., Koopmann, E., Friedrich, G., Voss, H., Schluter, T., Margolis, J., Platt, D., Swimmer, C., Gnirke, A., Chen, F., Vysotskaia, V., Mannhaupt, G., Guldener, U., Munsterkotter, M., Haase, D., Oesterheld, M., Mewes, H.-W., Mauceli, E. W., DeCaprio, D., Wade, C. M., Butler, J., Young, S., Jaffe, D. B., Calvo, S., Nusbaum, C., Galagan, J., and Birren, B. W. 2006. Insights from the genome of the biotrophic fungal plant pathogen Ustilago maydis. Nature 444:97-101.

Keon, J. P., White, G. A., and Hargreaves, J. A. 1991. Isolation, characterization and sequence of a gene conferring resistance to the systemic fungicide carboxin from the maize smut pathogen, Ustilago maydis. Curr. Genet. 19:475-481.

Khaldi, N., Collemare, J., Lebrun, M. H., and Wolfe, K. H. 2008. Evidence for horizontal transfer of a secondary metabolite gene cluster between fungi. Genome Biol. 9:R18.

Kruger, J., Loubradou, G., Wanner, G., Regenfelder, E., Feldbrugge, M., and Kahmann, R. 2000. Activation of the cAMP pathway in Ustilago maydis reduces fungal proliferation and teliospore formation in plant tumors. Mol. Plant-Microbe Interact. 13:1034-1040.

Kumar, S., and Punekar, N. S. 1997. The metabolism of 4-aminobutyrate (GABA) in fungi. Mycol. Res. 101:403-409.

Kusch, G., and Schauz, K. 1989. Light and electron microscopic studies of chlamydospore development in Ustilago maydis. Cryptogamic Bot. $1: 230-235$.

Langfelder, K., Philippe, B., Jahn, B., Latge, J. P., and Brakhage, A. A. 2001. Differential expression of the Aspergillus fumigatus pksP gene detected in vitro and in vivo with green fluorescent protein. Infect. Immun. 69:6411-6418.

Langfelder, K., Streibel, M., Jahn, B., Haase, G., and Brakhage, A. A. 2003. Biosynthesis of fungal melanins and their importance for human pathogenic fungi. Fungal Genet. Biol. 38:143-158.

Lin, S. Y., Okuda, S., Ikeda, K., Okuno, T., and Takano, Y. 2012. LAC2 encoding a secreted laccase is involved in appressorial melanization and conidial pigmentation in Colletotrichum orbiculare. Mol. PlantMicrobe Interact. 25:1552-1561.

Litvintseva, A. P., and Henson, J. M. 2002. Cloning, characterization, and transcription of three laccase genes from Gaeumannomyces graminis var. tritici, the Take-All fungus. Appl. Environ. Microbiol. 68:13051311.

Marita, J. M., Vermerris, W., Ralph, J., and Hatfield, R. D. 2003. Variations in the cell wall composition of maize brown midrib mutants. J. Agric. Food Chem. 51:1313-1321.

Martínez-Salgado, J. L., León-Ramírez, C. G., Pacheco, A. B., Ruiz-Herrera, J., and de la Rosa, A. P. B. 2013. Analysis of the regulation of the Ustilago maydis proteome by dimorphism, $\mathrm{pH}$ or MAPK and GCN5 genes. J. Proteom. 79:251-262.

Moriwaki, A., Kihara, J., Kobayashi, T., Tokunaga, T., Arase, S., and Honda, Y. 2004. Insertional mutagenesis and characterization of a polyketide synthase gene PKS1 required for melanin biosynthesis in Bipolaris oryzae. FEMS (Fed. Eur. Microbiol. Soc.) Microbiol. Lett. 238:1-8.

Oh, Y., Donofrio, N., Pan, H., Coughlan, S., Brown, D. E., Meng, S., Mitchell, T., and Dean, R. A. 2008. Transcriptome analysis reveals new insight into appressorium formation and function in the rice blast fungus Magnaporthe oryzae. Genome Biol. 9:R85.

Pfaffl, M. W. 2001. A new mathematical model for relative quantification in real-time RT-PCR. Nucleic Acids Res. 29:e45.

Piattelli, M., Fattorusso, E., Magno, S., and Nicolaus, R. A. 1963. Ustilago melanin, a naturally occurring catechol melanin. Tetrahedron Lett. 4:997-998.

Quadbeck-Seeger, C., Wanner, G., Huber, S., Kahmann, R., and Kamper, J. 2000. A protein with similarity to the human retinoblastoma binding 
protein 2 acts specifically as a repressor for genes regulated by the $\mathrm{b}$ mating type locus in Ustilago maydis. Mol. Microbiol. 38:154-166.

Reichmann, M., Jamnischek, A., Weinzierl, G., Ladendorf, O., Huber, S. Kahmann, R., and Kamper, J. 2002. The histone deacetylase Hda1 from Ustilago maydis is essential for spore development. Mol. Microbiol. 46:1169-1182.

Ruepp, A., Zollner, A., Maier, D., Albermann, K., Hani, J., Mokrejs, M., Tetko, I., Guldner, U., Mannhaupt, G., Munsterkotter, M., and Mewes, H. W. 2004. The FunCat, a functional annotation scheme for systematic classification of proteins from whole genomes. Nucleic Acid Res. 32:5539-5545.

Scherer, M., Heimel, K., Starke, V., and Kamper, J. 2006. The Clpl protein is required for clamp formation and pathogenic development of Ustilago maydis. Plant Cell 18:2388-2401.

Skibbe, D. S., Doehlemann, G., Fernandes, J., and Walbot, V. 2010. Maize tumors caused by Ustilago maydis require organ-specific genes in host and pathogen. Science 328:89-92.

Smith, D. G., Garcia-Pedrajas, M. D., Hong, W., Yu, Z., Gold, S. E., and Perlin, M. H. 2004. An ste20 homologue in Ustilago maydis plays a role in mating and pathogenicity. Eukaryot. Cell 3:180-189.

Snetselaar, K. M., and Mims, C. W. 1994. Light and electron-microscopy of Ustilago maydis hyphae in maize. Mycol. Res. 98:347-355.

Sugareva, V., Härtl, A., Brock, M., Hübner, K., Rohde, M., Heinekamp, T., and Brakhage, A. A. 2006. Characterisation of the laccase-encoding gene $a b r 2$ of the dihydroxynaphthalene-like melanin gene cluster of Aspergillus fumigatus. Arch. Microbiol. 186:345-355.

Tsai, H. F., Wheeler, M. H., Chang, Y. C., and Kwon-Chung, K. J. 1999. A developmentally regulated gene cluster involved in conidial pigment biosythesisy in Aspergillus fumigatus. J. Bacteriol. 181:64696477.
Tsai, H. F., Fujii, I., Watanabe, A., Wheeler, M. H., Chang, Y. C., Yasuoka, Y., Ebizuka, Y., and Kwong-Chung, K. J. 2001. Pentaketide melanin biosynthesis in Aspergillus fumigatus requires chain-length shortening of a heptaketide precursor. J. Biol. Chem. 276:29292-29298.

Tsukuda, T., Carleton, S., Fotheringham, S., and Holloman, W. 1988. Isolation and characterization of an autonomously replicating sequence from Ustilago maydis. Mol. Cell. Biol. 8:3703-3709.

Woo, P. C., Tam, E. W., Chong, K. T., Cai, J. J., Tung, E. T., Ngan, A. H., Lau, S. K., and Yuen, K. Y. 2010. High diversity of polyketide synthase genes and the melanin biosynthesis gene cluster in Penicillium marneffei. FEBS (Fed. Eur. Biochem. Soc.) J. 277:3750-3758.

Zhu, X., and Williamson, P. R. 2004. Role of laccase in the biology and virulence of Cryptococcus neoformans. FEMS (Fed. Eur. Microbiol. Soc.) Yeast Res. 5:1-10.

\section{AUTHOR-RECOMMENDED INTERNET RESOURCES}

GenomeNet motif search: motif.genome.jp

Institute of Bioinformatics and System Biology MIPS FunCat: www.helmholtz-muenchen.de/en/ibis/resourcesservices/services/funcatthe-functional-catalogue/index.html

Integrated DNA Technologies: www.idtdna.com/Home/Home.aspx

InterPro, Protein classification and analysis server: www.ebi.ac.uk/interpro MIPS Ustilago maydis genome database: mips.gsf.de/genre/proj/ustilago National Center for Biotechnology Information Gene Expression Omnibus: www.ncbi.nlm.nih.gov/geo/query/acc.cgi?acc=GSE54659 NimbleGen: www.nimblegen.com/index.html

Secretome 2.0 server: www.cbs.dtu.dk/services/SecretomeP SignalP 3.0 server: www.cbs.dtu.dk/services/SignalP-3.0 